\title{
Integrated Manufacturing of Aerospace Components by Superplastic Forming Technology
}

\author{
Kyung Ju Min ${ }^{a}$ and Ho-Sung Lee ${ }^{a^{*}}$ \\ ${ }^{a}$ Korea Aerospace Research Institute \\ 169-84 Gwahak-ro, Yuseong-gu, Daejeon 34133, Korea
}

\begin{abstract}
Aerospace vehicle requires lightweight structures to obtain weight saving and fuel efficiency. It is known that superplastic characteristics of some materials provide significant opportunity for forming complicated, lightweight components of aerospace structure. One of the most important advantages of using superplastic forming process is its simplicity to form integral parts and economy in tooling[1]. For instance, it can be applied to blow-forming, in which a metal sheet is deformed due to the pressure difference of hydrostatic gas on both sides of the sheet. Since the loading medium is gas pressure difference, this forming is different from conventional sheet metal forming technique in that this is stress-controlled rather than strain and strain rate controlled. This method is especially advantageous when several sheet metals are formed into complex shapes. In this study, it is demonstrated that superplastic forming process with titanium and steel alloy can be applied to manufacturing lightweight integral structures of aerospace structural parts and rocket propulsion components. The result shows that the technology to design and develop the forming process of superplastic forming can be applied for near net shape forming of a complex contour of a thrust chamber and a toroidal fuel tank.
\end{abstract}

\section{Introduction}

It is known that superplasticity is the ability of certain polycrystalline materials to extend plastically to large strains when deformed in tension. At appropriate superplastic deformation condition, some fine-grained metals have exhibited tensile elongation from several hundred to several thousand percent, while most crystalline solids can elongate by, at most, three or four percent without breaking[2]. In the presence of a suitable microstructure and temperature, superplasticity has been exhibited only over a narrow range of strain rates, typically about $10^{-2}$ to $10^{-5} \mathrm{per}$ sec. In general, since the strain rate is inversely related to grain size, the strain rate can increase with decreasing grain size or increasing temperature. When most metal is deformed by tension force, typical failure is due to the localized deformation and necking. However, during superplastic deformation, the metal will not neck because any local reduction in section leads to an increase in strain rate which in turn increases the flow stress[3]. Therefore, the strain rate sensitivity controls the degree of neck-free elongation. The effect of the rate of deformation on the flow stress is particularly important in superplasticity. It can describe the ability of the materials to resist necking. During superplastic deformation, the strain rate sensitivity of the flow stress has high values greater than 0.4 and may be used as an index of the degree of superplasticity to be expected at a given temperature. The higher the value of the strain rate sensitivity the more superplastic the alloy. The adoption of superplastic characteristics into manufacturing process provides significant advantage to make many of spacecraft components lighter and stiffer[4]. In superplastic forming $(\mathrm{SPF})$ process of sheet metals, one or more sheets of superplastic grade materials are heated and forced onto or into single surface tools by air pressure. Spacecraft components that can be produced using integrated superplastic forming include complex, secondary structural parts that require high local deformations in one forming operation with diffusion bonding[5].

\section{Titanium toroidal tank}

In spacecraft system, toroidal tanks for a bipropellant propulsion system can be more effective than cylindrical tanks. Even though the toroidal tanks are heavier and more expensive to manufacture than the cylindrical tanks, this design provides many advantages. It is possible to obtain a more symmetrical distribution of fuel mass and a smaller variation in the position of the vehicle center-of-mass during fuel consumption would result, reducing requirements for attitude control propellants, for balance weight, and for other weights associated with the dynamics of the spinning spacecraft[6]. In order to manufacture a

\footnotetext{
*hslee@kari.re.kr
} 
titanium toroidal tank, typical manufacturing technologies like spin forming, stamping, roll bending would be utilized followed by welding. In this case, the formed parts should have a good tolerance in mating locations in order to obtain defect free and geometrically precise final product. However, in case of using superplastic forming technology, it is relatively easy to control the tolerance in mating location because the assembly of each part, which will be formed into the each corresponding component, is conducted before forming[7,8].

The flow stress to obtain superplastic behavior of Ti6Al4V was obtained from a series of tensile tests with strain rates ranged from $10^{-4} / \mathrm{sec}$ to $10^{-2} / \mathrm{sec}$ and at several temperatures of $1073 \mathrm{~K}$ to $1223 \mathrm{~K}$. The typical flow stress curve is shown in Fig. 1. The maximum elongation was obtained at the strain rate of $10^{-3} \mathrm{~s}-1$ and $1123 \mathrm{~K}$.
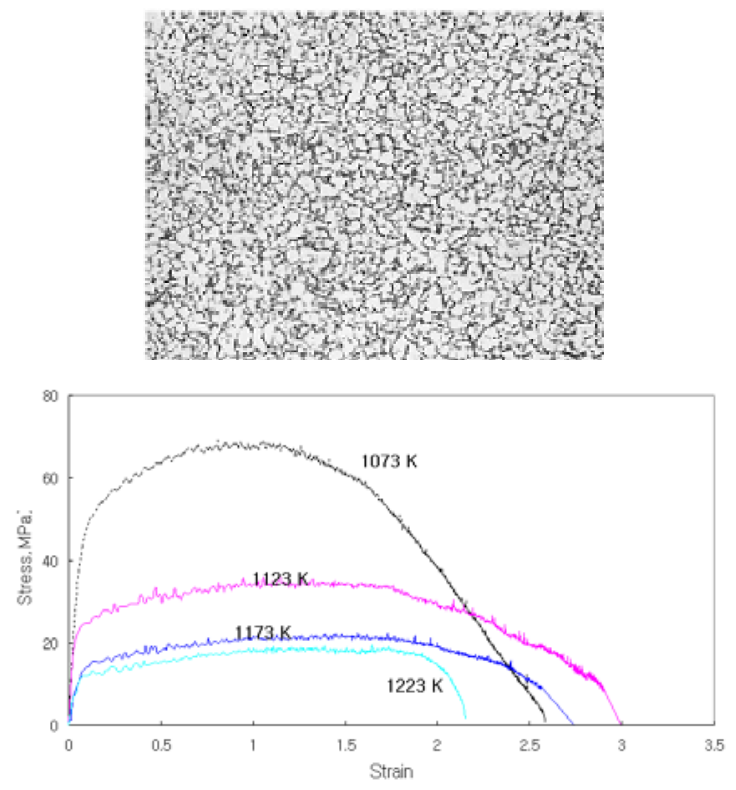

Figure 1 Microstructure and flow stress curves at strain rate of

$$
10^{-4} / \mathrm{sec}
$$

After determining superplastic characteristics of this alloy, the forming profile was prepared from a finite element analysis(FEM) with MARC(MSC Software Corp.). The schematic shape of the toroidal tank for ramjet engine in subscale is show in Figure 2 with design drawing of toroidal tank[4]. The outer diameter is $150 \mathrm{~mm}$ and inner diameter is $90 \mathrm{~mm}$ in quarter subscale. The present work was concerned with fabrication of this tank with superplastic forming of Ti-6Al-4V sheets. Since the superplastic forming temperature is above $1073 \mathrm{~K}$, corrosion resistant steel (CRES) is chosen for tool material. The detailed forming fixture is described in Figure 2[8]. It is important to drill a hole for gas supply. In the figure, the gas inlet hole is located at the left side of the tool. The hydrostatic gas pressure will be applied inside of the tank for final forming. The inner sheet and outer sheet are tungsten inert gas arc welded and the specimen is located inside of the forming tool(Fig. 3b) and inert gas will be applied. The hydrostatic gas pressure profile was obtained from the finite element simulation[9] and the gas pressure increases almost linearly up to the maximum pressure of 15 bar.
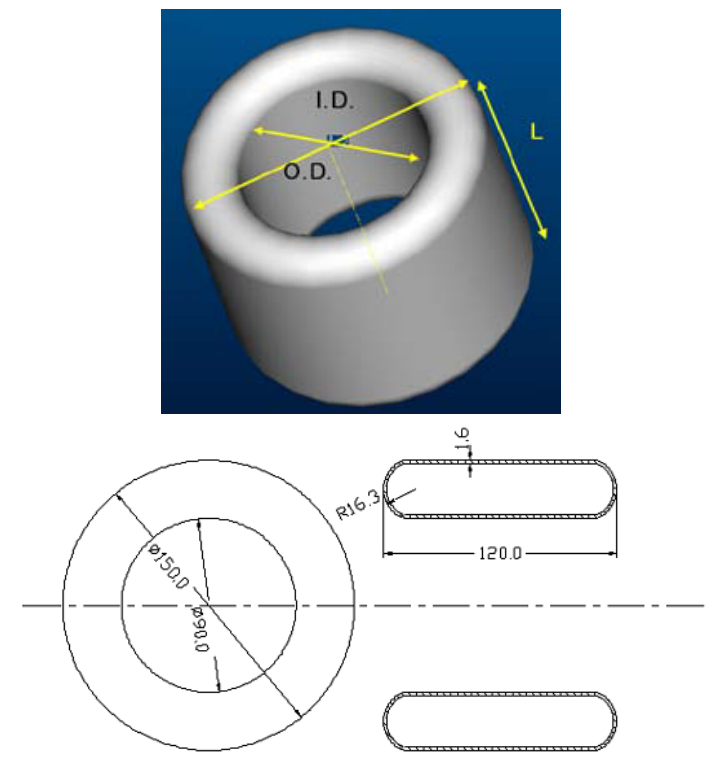

Figure 2 Schematic shape of toroidal tank and cross-sectional drawing[7]

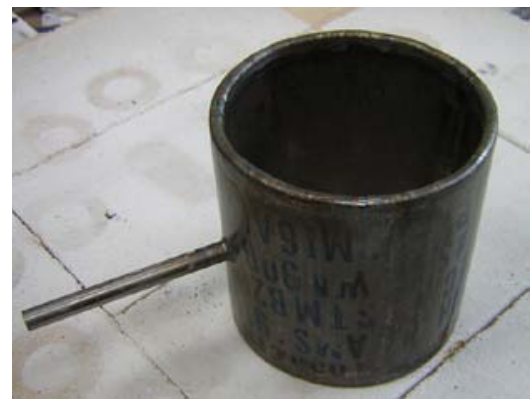

(a ) pre-welded double tube

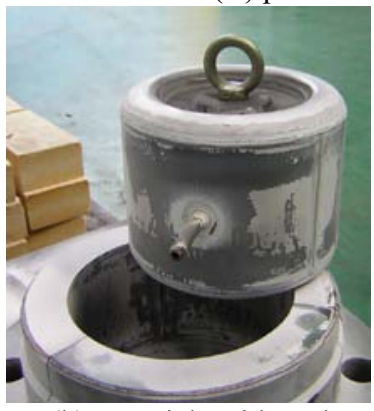

(b) an article with tools

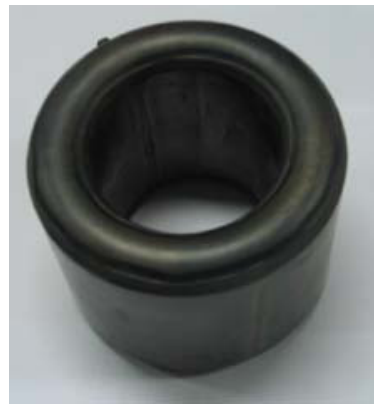

(c) formed article
Figure 3 Schematic shape of toroidal tank and cross-sectional drawing

\section{Duplex steel thrust chamber with copper channels}

Regenerative cooling chamber is composed of copper alloy for inner wall with cooling channels and steel for outer jacket. Because of its high thermal conductivity, copper alloy is suitable for the inner wall and does not 
oxidize in fuel rich gas mixtures. The outer jacket is made of dual phase stainless steel due to its high toughness and strength to sustain the internal pressure. In this study, the outer skin was formed with superplastic blow forming and diffusion bonded with inner liner made of copper alloy. For inner liner, copper alloy was machined for cooling channels and then placed in the diffusion welding fixture. It is important to evaluate the contour with steel outer skin for complete match. The tool design and forming process were reviewed in detail, since the cost of high temperature tool material is expensive. In order to characterize the flow strength of dual phase stainless steel(SUS329J1) at high temperatures, several tensile tests were performed at temperatures from 800 to $950^{\circ} \mathrm{C}$. A series of flow stress was obtained from high temperature tensile tests with strain rates ranged from $10^{-4} / \mathrm{sec}$ to $10^{-2} / \mathrm{sec}$ and at several temperatures from $900^{\circ} \mathrm{C}$ to $1050^{\circ} \mathrm{C}$. The optimum condition was obtained at a strain rate of $10^{-4} / \mathrm{sec}$, the elongation of $552 \%$ and UTS was $13 \mathrm{MPa}$ at $980^{\circ} \mathrm{C}[10]$. Superplastic forming procedure for stainless steel outer jacket is shown in Figure 4. The hydrostatic gas pressure of maximum 7Mpa was supplied inside copper inner layer and a chamber prototype was successfully manufactured (Figure 5).

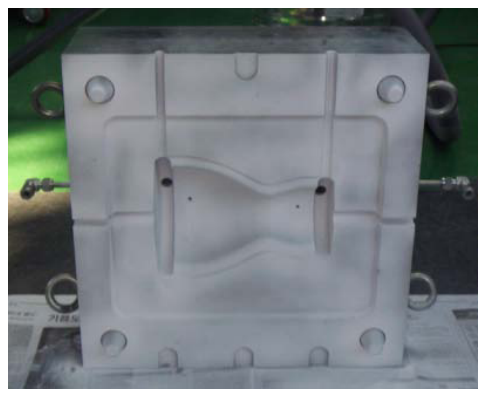

(a)

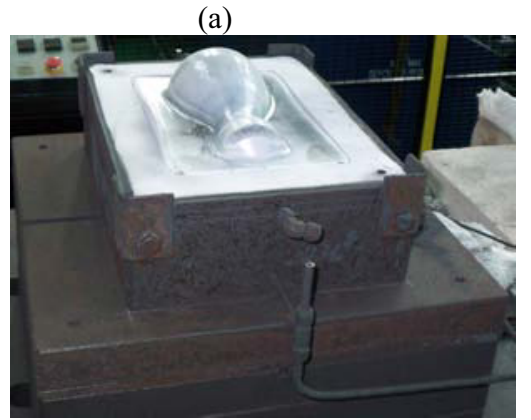

(b)

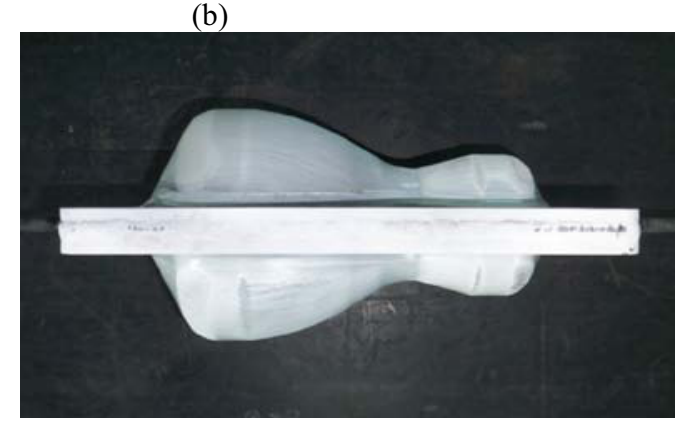

(c)

Figure 4. Photographs of concave die(a), steel sheet after superplastic forming(b), and formed outer skin article(c) [10]
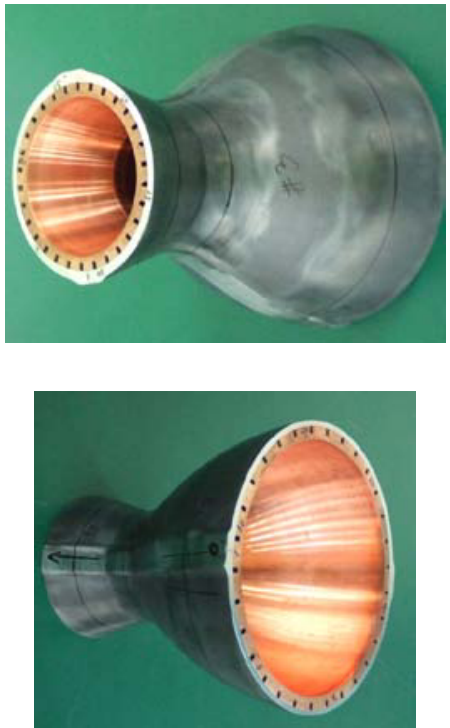

Figure 5. Photographs of thrust chamber with copper cooling channels[11]

\section{Summary}

The present study demonstrates that the superplastic forming process can be applied to fabricate integrated aerospace components with complex figure. Titanium toroidal tank was manufactured with applying hydrostatic gas pressure and the thrurst chamber with dual phase stainless steel and copper inner channels was successfully formed with superplastic forming technology.

\section{References}

1. Mukherjee, A. K., Gurewitz, G., and Meier, M., Fundamental Investigations of Failure during Superplastic Forming Process, AFOSR-TR-83-0106, AFOSR/NE(1983).

2. Mukherjee, A. K., Superplasticity in Metals, Ceramics and Intermetallics: Materials Science and Technology, Willey-VCH Velag, 2006.

3. Mukherjee, A. K., Mater. Sci. Eng., 8(1971), pp. 83-89.

4. Giuliano, G., Superplastic Forming of Advanced Metallic Materials, June 2011, Woodhead Publishing, Cambridge, U.K.

5. Chaturvedi, M. C., Welding and Joining of Aerospace Materials, Chapter 10, December 2011, Woodhead Publishing, Cambridge, U.K.

6. Anderson, J. E., NASA-CR-137584, October 1974.

7. Ho-Sung Lee, et. al., SAE Int.J.Aerosp.2 (2010) pp.258-262, 2010.

8. Ho-Sung Lee, et. al., Key Engineering Materials Vol. 433 (2010) pp 57-62.

9. Jong-Hoon Yoon, et. al., Materials Science Forum Vol. 735 (2013) pp 240-245.

10. Ho-Sung Lee, et. al., Applied Mechanics and Materials Vol. 87 (2011) pp 132-135.

11. Ho-Sung Lee, et. al., Materialwissenschaft und Werkstofftechnik, Vol. 42(2011) pp.985-989. 